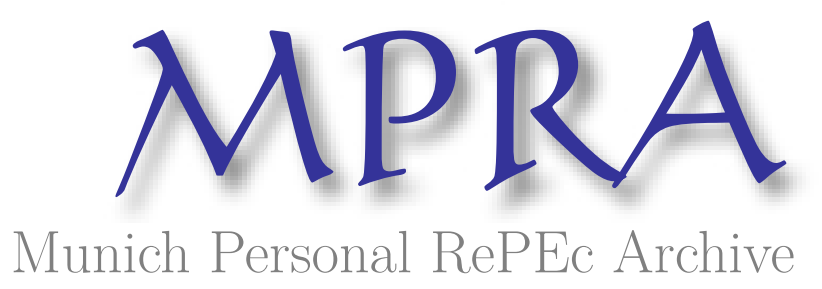

\title{
Household Income Determination and Regional Income Differential in Rural China
}

meng, xin and wu, harry

Economics, Research School of Pacific and Asian Studies, Australian national University

1994

Online at https://mpra.ub.uni-muenchen.de/1345/

MPRA Paper No. 1345, posted 06 Jan 2007 UTC 


\title{
Household Income Determination and Regional Income Differential in Rural China
}

\author{
by \\ Xin Meng \\ Australian National University \\ and \\ Harry $X . W u$ \\ University of Adelaide \\ Hone Kong Polytechnic University
}

\begin{abstract}
Regional income dispersion is a sensitive issue in China in terms of judging the impact of economic reform. This study looks closely at the issue as to what are the determinants of income variation among households in general, and which are the key determinants of income dispersion among different regions. The study uses the data from a sample survey on 1000 rural households in five Chinese provinces. Household income equations are estimated to assess the determinants of income variations among China's rural households. Blinder's (1973) decomposition approach is used to determine whether the regional income differential is mostly due to regional endowment differential or regional premium. Among other interesting findings, the major determinant of regional income dispersion seems to be the degree of regional marketisation. Moreover, the rate of return to most factors is significantly different across regions. These findings suggest that further economic reform in less developed regions and the open up of inter-regional trade and factor mobility are the most important factors in reducing the regional income differential.
\end{abstract}

JEL classification codes: R2 and J4

We wish to thank Christopher Findlay, Ross Ganuat, Steven Lim, Paul Miller, Warwick McKibbin, Tin Nguyen, Jonathan Pincus, Richard Pomfret, Corrie Reiman Peter Summers, and anonymous referee for very helpful suggestions and comments. The financial support under the ACIAR (Australian Centre of International Agricultural Research) Grain Project on China is gratefully acknowledged. 


\section{Introduction}

The dispersion of China's regional development has widened dramatically since economic reform began in the late 1970s. Economic growth in some coastal provinces, such as Guangdong and Shandong, is far more rapid than that in inland regions, especially with regard to the respective rural areas. This disparity leads to the dispersion of regional income distribution, particularly in rural areas. In 1978, for example, the coefficient of variation of per capita rural income among 28 provinces was 0.33 , whereas it increased to 0.49 in $1993{ }^{1}$

Although it is easy to interpret this increased degree of income dispersion as a direct result of economic reform, very little information has been available to explain why this is so. This study, therefore, looks closely at the issue of what the general determinants of income variation among households are and what the key determinants affecting income dispersion among different regions are.

The study uses the data from a sample survey of about 1000 rural households in five of China's provinces. Household income equations are estimated to assess the determinants of income variations among the households. Blinder's (1973) decomposition approach is used to determine whether the regional income differential is due mostly to a regional endowment differential or a regional premium. The latter includes the stage of regional economic development, the degree of marketisation, the openness of the regional economy, and any other influential economic factors which relate specifically to the location of a particular region.

The paper is structured as follows. The next section provides background information on the dispersion of regional development for the 5 provinces studied in this paper over the reform period. Section 3 specifies the model for empirical examination. Section 4 discusses the econometric results of the two income equations used for the total sample as well as for each individual province. This, then, gives a basic idea about the determinants of income variation among households. The following section decomposes the income differentials among the regions studied to determine the causes of regional income dispersion. Concluding remarks and policy implications are given in the last section.

1 The coefficient of variation presented here are calculated using the data from Statistical Yearbook of China 1994. 


\section{Background to the dispersion of regional development over the reform period using official and survey data}

The data used in this study came from a sample survey of about 1000 rural households across five of China's provinces, namely Guangdong, Jilin, Jiangxi, Sichuan and Shandong. ${ }^{2}$ The survey was conducted in 1993-1994. It is worthwhile to briefly review the background of the disparity of economic development across these provinces over the reform period. The survey results of each province can then be examined against their respective economic background.

The five surveyed provinces are located in different parts of China and have experienced different patterns of economic development since the late 1970s when economic reform began. The historical pattern of regional development was largely determined by differences in resource endowment (both natural and human resources). However, reallocation of resources, which was affected by national plans during the central planning period (1949-1977) and then by different reform policies throughout the economic reform period (1978-now), played a significant role in re-shaping regional development.

Both Guangdong and Shandong are located in China's coastal region where the local economy is more developed than that of the central and western regions. However, by the time that economic reform was introduced, the economic performance of both regions was only moderate. As Table 1 shows, the 1978 per capita GDP for Guangdong (365 yuan) was close to the national level of 373 yuan, whereas Shandong (328 yuan) was at about 90 per cent of the national level. Both regions rated below Jilin (405 yuan) but well above Jiangxi (258 yuan) and Sichuan (237 yuan). It should be noted that the reason that Jilin had the highest per capita GDP level among the five provinces is attributed not only to the highest level of natural resource endowment, but also to its highest per capita investment in fixed capital between 1953 and 1975. Taking the arable land per rural labourer in the beginning of the reform as a proxy for natural resource endowments, it was $19 \mathrm{mu}$ for Jilin, compared with the average of $4.9 \mathrm{mu}$ for the nation and 3.4, 2.8, 4.4 and $2.4 m u$ for Jiangxi, Sichuan, Shandong and Guangdong, respectively (Table 1). Using the state investment in fixed capital during 1953-75 on a per capita basis as a proxy for total capital investment, it was 739 yuan for Jilin, well above the national level of 536 yuan, and 324, 427, 279 and 322 yuan for Jiangxi, Sichuan, Shandong and Guangdong, respectively. Higher investment in fixed capital could also largely explain a higher urbanisation level, which was 31 per cent for Jilin in

2 See Appendix A for the background to the survey and more details about the survey data. 
1978, compared to $14,12,10$ and 16 per cent for Jiangxi, Sichuan, Shandong and Guangdong, respectively (Table 1).

The lowest level of per capita state investment in the two coastal provinces of Guangdong and Shandong clearly shows the effect of resource reallocation policy during the central planning period, which aimed to gain a more 'balanced' growth across regions in a closed economic framework. Following economic reform, the coastal regions grew faster than others. This was brought about by higher degree of marketisation and greater openness of these regional economies. Guangdong was the province that gained the most advantage from the reform in the late 1970s and Shandong also benefited significantly from the second stage of the nation's opening-up strategy in the mid-1980s. As Table 1 shows, over the period of 1978-93, the real GDP growth was 13 per cent for Guangdong and 10.3 per cent for Shandong, well above the national average of 8.9 per cent. By 1993, Guangdong had replaced Sichuan as the largest regional economy (in terms of GDP level) among the five provinces. Meanwhile, in terms of per capita income, Jilin, with the slowest growth rate despite the highest resource endowment level among the five provinces, fell far behind both Guangdong and Shandong. Obviously, more favorable reform policies and a distinct location advantage have played greater roles than resource endowment in the post-reform growth of the coastal provinces. On the other hand, the existing factor endowment still counted considerably when policy and location conditions are about the same. For example, despite their faster growth over the reform period both Jiangxi and Sichuan's per capita GDP level was still far less than that of Jilin in 1993 (Table 1). 
TABLE 1 Some key statistics to Guangdong, Jilin, Jiangxi, Sichuan and Shandong, as well as for the Chinese economy as a whole, 1978 and 1993

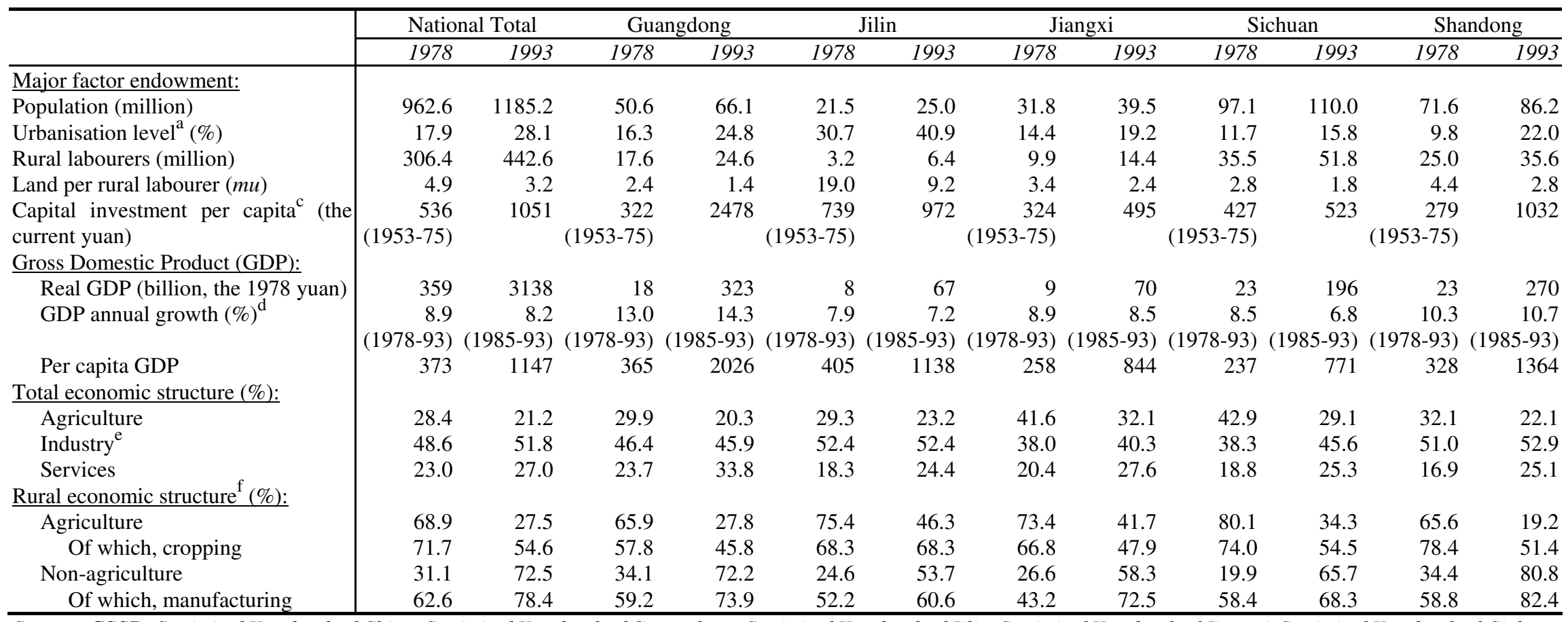

Sources:CSSB: Statistical Yearbook of China, Statistical Yearbook of Guangdong, Statistical Yearbook of Jilin, Statistical Yearbook of Jiangxi, Statistical Yearbook of Sichuan, and Statistical Yearbook of Shandong, various volumes between 1985 and 1994. Calculations applied.

Notes: a. Due to problematic aspects of urban population data, the urbanisation level for provinces is measured as the ratio of the population with non-agricultural

residential statues (hukou) to the total population. Urbanisation level for the economy as a whole is derived from the official data that was recently adjusted.

b. Refers to the entire workforce in the rural sector, including agricultural and non-agricultural components.

c. The per capita accumulative investment in 1953-75 is state investment only, while the per capita investment in 1995 is the contribution by all investors.

$\mathrm{d}$. The annual growth rate is estimated by regressing GDP against the time trend in order to get rid of abnormal fluctuations over time.

e. Including mining, manufacturing and construction.

f. The first year is 1980 rather than 1978 . No data for 1978 was available. 
China's rapid post-reform growth has resulted in rapid structural changes as well. These structural changes, however, have also been uneven across regions. This is another important factor that has attributed to the dispersion of income across regions. All the five provinces studied have experienced a big drop in the agricultural share and a sharp rise in the service share of their total GDP. Once again, Guangdong and Shandong have been the leading provinces. A significant increase in the service sector reflects a fast pace in commercialisation or marketisation. This is driven by the reform and has close link to income growth. By contrast, the industrial share in GDP has started to decline in the faster growing provinces. From the viewpoint of this paper, it is particularly worthwhile to examine the structural change in the rural economy. A distinct feature of post-reform structural change in rural China has been a rapid decline in the cropping share of total farm production and a fast increase in the rural manufacturing share of overall off-farm production $(\mathrm{Wu}, 1994 \mathrm{a})$. All the five provinces have experienced rapid structural changes in their rural economy, but the imbalance of the changing pace among them has remained. For example, as Table 1 shows, from 1980 to 1993, the agricultural share of rural GOV (gross output value) for Guangdong reduced from 65.9 to 27.8 per cent, of which the cropping share declined from 57.8 to 45.8 per cent. The corresponding figures for Shandong were from 65.6 to 19.2 per cent and from 78.4 to 51.4 per cent. Jilin had the smallest change in this regard: its agricultural share in the rural GOV declined from 75.4 to 46.3 per cent, whereas its cropping share of agricultural production remained unchanged. While the non-agricultural share of the rural GOV has risen rapidly, the manufacturing share in this sector has also increased. For example, by 1993, 72.2 per cent of rural GOV in Guangdong had become non-agricultural, of which 73.9 per cent was manufacturing. The corresponding figures for Shandong were even higher (80.8 and 82.4 per cent, respectively) and for Jilin they were much lower (53.7 and 60.6 per cent, respectively). 
TABLE 2 Summary statistics-1993-94 rural household survey conducted in Guangdong, Jilin, Jiangxi, Sichuan and Shandong

\begin{tabular}{|c|c|c|c|c|c|c|c|c|c|c|c|c|}
\hline & \multicolumn{2}{|c|}{ Total } & \multicolumn{2}{|c|}{ Guangdong } & \multicolumn{2}{|c|}{ Jilin } & \multicolumn{2}{|c|}{ Jiangxi } & \multicolumn{2}{|c|}{ Sichuan } & \multicolumn{2}{|c|}{ Shandong } \\
\hline & Mean & c.v. & Mean & c.v. & Mean & c.v. & Mean & c.v. & Mean & c.v. & Mean & c.v. \\
\hline Household net income (yuan)* & 5788 & 1.33 & 12318 & 1.01 & 3894 & 0.71 & 4638 & 1.50 & 2331 & 0.94 & 4853 & 0.46 \\
\hline Income per labour (yuan) & 1689 & 1.20 & 3371 & 1.01 & 1181 & 0.83 & 1317 & 0.93 & 687 & 1.28 & 1650 & 0.50 \\
\hline Income per capita (yuan) & 1272 & 1.16 & 2492 & 1.00 & 897 & 0.75 & 989 & 0.96 & 554 & 1.01 & 1259 & 0.47 \\
\hline Share of family production income & 0.82 & 0.26 & 0.77 & 0.32 & 0.93 & 0.13 & 0.83 & 0.22 & 0.80 & 0.27 & 0.78 & 0.30 \\
\hline Share of agricultural income & 0.70 & 0.35 & 0.62 & 0.45 & 0.88 & 0.20 & 0.74 & 0.28 & 0.63 & 0.34 & 0.64 & 0.37 \\
\hline Share of outside family income & 0.18 & 1.17 & 0.23 & 1.09 & 0.07 & 1.86 & 0.17 & 1.06 & 0.20 & 1.10 & 0.22 & 1.07 \\
\hline Schooling per labour (year) & 6.3 & 0.39 & 6.3 & 0.33 & 6.7 & 0.51 & 5.9 & 0.37 & 5.9 & 0.37 & 6.8 & 0.32 \\
\hline Experience per labour (year) & 23.5 & 0.31 & 24.1 & 0.28 & 24.2 & 0.30 & 20.9 & 0.28 & 24.5 & 0.33 & 23.8 & 0.31 \\
\hline Family labour participation rate & 0.78 & 0.27 & 0.78 & 0.28 & 0.79 & 0.24 & 0.77 & 0.29 & 0.81 & 0.26 & 0.79 & 0.25 \\
\hline Female labour participation rate & 0.48 & 0.31 & 0.47 & 0.32 & 0.48 & 0.31 & 0.50 & 0.32 & 0.49 & 0.37 & 0.49 & 0.29 \\
\hline Total land contracted (mu) & 9.76 & 1.01 & 8.69 & 1.48 & 20.61 & 0.51 & 7.92 & 0.54 & 3.79 & 0.35 & 7.02 & 0.43 \\
\hline Land per labour $(\mathrm{mu})$ & 3.08 & 1.05 & 2.60 & 1.49 & 6.40 & 0.63 & 2.45 & 0.62 & 1.26 & 0.43 & 2.49 & 0.54 \\
\hline Land per capita (mu) & 2.26 & 1.04 & 1.78 & 1.49 & 4.89 & 0.61 & 1.73 & 0.51 & 0.94 & 0.31 & 1.84 & 0.48 \\
\hline Total capital owned (yuan)* & 2021 & 1.43 & 1267 & 2.41 & 3993 & 0.98 & 1811 & 0.83 & 538 & 1.53 & 2368 & 1.09 \\
\hline Capital per labour (yuan) & 633 & 1.50 & 353 & 2.43 & 1186 & 1.03 & 535 & 0.92 & 207 & 2.13 & 859 & 1.28 \\
\hline Capital per capita (yuan) & 474 & 1.46 & 260 & 2.52 & 923 & 1.01 & 401 & 0.94 & 141 & 1.64 & 622 & 1.11 \\
\hline Working days per labour (day) & 235 & 0.35 & 282 & 0.20 & 123 & 0.51 & 246 & 0.27 & 270 & 0.16 & 256 & 0.21 \\
\hline Proportion of agr. working days & 0.69 & 0.38 & 0.64 & 0.45 & 0.85 & 0.26 & 0.74 & 0.30 & 0.63 & 0.37 & 0.60 & 0.38 \\
\hline Number of observations & 1876 & & 406 & & 380 & & 396 & & 328 & & 366 & \\
\hline
\end{tabular}

Source: The rural household survey data are from the rural household survey on China's grain production and marketing conducted by the Chinese Economy Research Unit, University of Adelaide and the Ministry of Agriculture, PRC with the financial support of ACIAR (Australian Centre for International Agricultural Research).

Note: $\quad$ Mean= arithmetic mean; c.v.= coefficient of variation. * Data on income and capital are deflated (Appendix A) 

Without question, increases in income and changes in structure are associated with other deepened changes in an economy that may affect income growth in the future. These changes include, for example, changes in education level (both general and occupational), working skills, labour participation rate and capital accumulation, and reallocation of resources (including land, capital, as well as labour) across sectors. Changes in such factors were recorded by the sample survey of 1000 rural households across the five sample provinces. Based on the survey data, Table 2 reports summaries of the mean of income variables and of the major factors that are likely to be related to income growth, which may have contributed to income dispersion across the provinces.

As reflected by the official data presented in Table 1, the households in rural Guangdong and Shandong were still leading ones in almost all income indicators among the surveyed households across the five provinces. The household per capita income is taken as an illustrative example as it is a better measure of household income in comparison to household total and per labourer income. As Table 2 shows, the average household per capita income was 2492 yuan for Guangdong, which almost doubled that of Shandong (1259 yuan), the second highest level of rural household per capita income in the survey. Sichuan was at the bottom of the rank with an average household per capita income of only 554 yuan.

The impact of structural change upon income dispersion is clearly reflected by the difference in the source of income across provinces. For example, in Guangdong 38 per cent of household income came from non-agricultural activities. Both Shandong and Sichuan also had a similar proportion of income from such activities. In Jilin, however, the figure was only about 12 per cent. In Guangdong and Shandong, more than 20 per cent of household income came from the outside-family production, while in Jilin, the figure was only 7 per cent. Sichuan was again very close to the level of the two coastal provinces, largely reflecting its very low land endowment per labourer that forced more labourers to seek off-farm activities, either within or outside the family.

Table 2 also reports the indicators for the factor endowment related to the income of a rural household. For physical capital, households in rural Jilin had the largest arable land (20.6 $\mathrm{mu}$ ) and fixed capital (3993 yuan), while households in rural Sichuan, the most populous province in China, had the least arable land (1.26 $\mathrm{mu}$ ) and fixed capital (538 yuan).

As for the human capital endowment, the survey data only revealed smaller differences across the surveyed provinces. It shows that labourers in rural Guangdong and Shandong had a slightly higher schooling than their counterparts in other provinces. 
The households in Sichuan had the highest family labour participation rate (0.81) and the households in Jiangxi had the highest female labour participation rate (0.50). The rate of average working days over expected working days, which we assume to be 330 days per year, is ranked ascendantly as follows: Jilin (32\%), Jiangxi (71\%), Shandong (73\%), Guangdong (74\%), and Sichuan (81\%). It is clear that Jilin has too much seasonal surplus labour, whereas the rest of the regions have virtually the same level of seasonal surplus labour.

Jilin province is in Northeast China, where a cold climate provides only one cropping season. This might partly explain the very short average working days per labourer in Jilin. More importantly, this also suggests that there is a lack of non-agricultural employment opportunity and particularly lack of labour mobility in Jilin as the data for total working days also includes non-agricultural working days both within and outside a household. The ratio of agricultural working days over the total working days for Jilin suggests that on average 85 per cent of labour working days were allocated to agricultural production, compared with that of about 60 per cent in Shandong, Sichuan and Guangdong. This also confirms the conjecture of lack of non-agricultural activity in Jilin.

The other interesting case is Sichuan, where average working days accounts for 81 per cent of expected working days. Among the five provinces, Sichuan has the lowest level of arable land per labourer. Considering the fact that on average only 56 per cent of total labour working days were allocated to agricultural production, we might conclude that the non-agricultural employment opportunity is more adequate in Sichuan than that in Jilin and Jiangxi. Or, this might also suggest that labour mobility in Sichuan is less restricted.

\section{Model Specification}

To analyse the determinants of household income variation we specified two income equations, namely the household net income and the household per capita income. The household per capita income is a better measure of household income compared to the household net income as it takes the difference of family size into account (Kuznets, 1976; Datta and Meerman, 1980).

In rural China, household net income is normally comprised of two major portions: the net income from household production and the total wage earned by household labourers who work elsewhere. Hence, a household net income function can be specified as 


$$
\begin{aligned}
H N I_{i} & =N R_{i}^{F}+w_{i}^{O} L_{i}^{O} \\
& =p Q_{i}\left(X_{i}^{F}, Z_{i}\right)-p_{Z} Z_{i}+w_{i}^{O} L_{i}^{O} \\
& =\left(p-p_{Z} Z_{i} / Q_{i}\right) Q_{i}+E_{i} \\
& =\tilde{p} Q_{i}+E_{i}
\end{aligned}
$$

where $H N I_{i} \quad$ is the $i$ th household's net income,

$N R_{i}^{F} \quad$ is the $i$ th household's net revenue, superscript $F$ denotes family,

$w_{i}^{O} L_{i}^{O} \quad$ is the wage earned by $i$ th household's labourers who work elsewhere (denoted by superscript $O$ ),

$p \quad$ is the price of output,

$p_{Z} \quad$ is a scalar of price for hired inputs,

$X_{i}^{F} \quad$ is a vector of household production inputs which are owned by the household (not including household labourers who work elsewhere),

$Z_{i} \quad$ is a vector of household production inputs which are hired by the household,

$\tilde{p} \quad$ is equal to $p-p_{Z} Z_{i} / Q_{i}$

$E_{i} \quad$ is the total income earned by those household members who work elsewhere,

The first term of Equation (1) is $\tilde{p}$ times the household production function. An assumption that needs to be made here is that all households in our sample use identical production technology. This is a rather strong, but necessary, assumption as the data used in this study did not allow us to estimate separate production functions for each household. We specify the production function in the form of Cobb-Douglas in this study.

Assume $\tilde{p}=\overline{\tilde{p}} * \varepsilon_{i}$, where $\overline{\tilde{p}}$ is the mean value of $\tilde{p}$, and $\varepsilon_{i}$ is the noise term. Equation (1) can then be written as

$$
H N I_{i}=\overline{\tilde{p}} Q_{i} \varepsilon_{i}+E_{i}
$$

To take the logarithmic transformation of Equation 2, we take $E_{i}$ to the left-hand side of the equation and rearrange it to obtain

$$
\ln \left(H N I_{i}-E_{i}\right)=\ln \overline{\tilde{p}}+\ln Q_{i}+\ln \varepsilon_{i}
$$

Following the new growth theory (see Romer, 1986 and 1990; Lucas, 1988; Caballe, 1993), human capital should contribute significantly to household production, the production function is then specified as:

$$
Q_{i}=f_{i}\left(L_{i}^{F}, K_{i}, L L_{i}, S_{i}, \exp _{i}, \exp _{i}^{2}\right)
$$

where $\quad L_{i}^{F} \quad$ is labour inputs used within household production,

$K_{i} \quad$ is capital stock,

$L L_{i} \quad$ is arable land contracted by the household,

$S_{i} \quad$ is years of schooling per labour, 
$\exp _{i} \quad$ is years of labour market experience per labourer,

$\exp _{i}^{2}$ is the quadratic term of $\exp$.

Taking the Cobb-Douglas specification of the production function and assuming that the quantity of labour, capital and land have logarithmic relationships with output and further assuming that the human capital variables have semi-log relationship with the output, the production function can then be written as

$$
Q_{i}=A\left(L_{i}^{f}\right)^{\beta_{1}} K_{i}^{\beta_{2}} L L_{i}^{\beta_{3}} e^{\beta_{4} S_{i}} e^{\beta_{5} \exp _{i}} e^{\beta_{6} \exp _{i}^{2}} u_{i}
$$

Substituting equation 5 into equation 3 , we obtain

$$
\begin{aligned}
\ln \left(H N I_{i}-E_{i}\right) & =\ln \overline{\tilde{p}}+\ln A+\beta_{1} \ln L_{i}+\beta_{2} \ln K_{i}+\beta_{3} \ln L L_{i} \\
& +\beta_{4} S_{i}+\beta_{5} \exp _{i}+\beta_{6} \exp _{i}^{2}+v_{i}
\end{aligned}
$$

where $v_{i}=\ln \varepsilon_{i}+\ln u_{i}$.

However, the data used in this study does not allow us to separate the quantity and quality of labourers who work elsewhere from those who work within the household. On the other hand, according to human capital theory, outside earning (market wage rate) of individual $i$ is a function of his/her possessed human capital and some other demographic variables (Becker, 1962; Mincer, 1974). This may be specified as

$$
E_{i}=\alpha_{0}+\alpha_{1} S_{i}+\alpha_{2} \exp +\alpha_{3} \exp _{i}^{2}+e_{i}
$$

The set of human capital variables we are able to use in this study are average years of schooling per household labourer, average years of potential labour market experience per household labourer using Mincer's (1974) approach, and a quadratic term of the potential experience. The inclusion of the set of human capital variables, therefore, captures both the impacts of these variables on household production and on the variations of household outside earnings. Hence the specification of Equation 6 may be approximated as:

$$
\begin{aligned}
\ln H N I_{i}= & \gamma_{0}+\gamma_{1} \ln L_{i}+\gamma_{2} \ln K_{i}+\gamma_{3} \ln L L_{i} \\
& +\gamma_{4} S_{i}+\gamma_{5} \exp _{i}+\gamma_{6} \exp _{i}^{2}+v_{i}
\end{aligned}
$$

The term $\gamma_{0}$ comprises three components: $\ln A$ from the Cobb-Douglas production function, $\ln \overline{\tilde{p}}$ from the household net revenue function and, possibly, $\alpha_{0}$ from Mincer's specification of earnings function. The terms $\gamma_{4}, \gamma_{5}$, and $\gamma_{6}$ comprise components both from household production and outside earnings equations.

Some demographic variables are also included in this study. They are the family size (number of household members) and the household female labour ratio (the number of household female labourers over the total number of household labourers). 
The first variable might be important for net income per capita within the household as only labourers create income within a household.

The second variable is included to test whether female labour is equally productive when compared with male labour. A gender wage differential is a widely observed phenomena in world economies, however, most studies of this issue are unable to control for the fact that this differential might come from either their endowment differential or employers' discrimination. ${ }^{3}$ This study provides a relatively controlled situation, where households are assumed to allocate their production capacity so as to maximise family net income. As the households studied here are also production units, they would fully utilise the amount of labour available within the household. Hence, we should not expect any discrimination against female labourers. By controlling other household production and human capital variables, a negative impact of female ratio would imply a lower productivity of female labourers compared with male labourers and vice versa. If this variable has no significant impact on household income we would conclude that female and male labourers are equally productive.

As income data collected in the survey is the yearly income of households, a variable of actual working days of household labour is included in the income equation. The reason for adding this variable is that there are ample surplus labourers in some of China's rural regions. Part of this surplus labour is seasonal and the impact of this kind of surplus labour on household income can be captured by the variation of average labour working days of each household.

In addition, the share of agricultural production working days per household labourer is included to test whether the agricultural production contributes positively or negatively to household net income.

Apart from the variables mentioned above, a set of regional dummy variables and a time dummy variable for 1994 are also included in the estimated income equations. The final estimated household income equation may be fully specified as the following:

$$
\begin{aligned}
\ln H I_{i} & =\gamma_{0}+\gamma_{1} \ln L_{i}^{8}+\gamma_{2} \ln K_{i}+\gamma_{3} \ln L L_{i}+\gamma_{4} \text { edu }_{i}+\gamma_{5} \exp _{i}+\gamma_{6} \exp _{i}^{2} \\
& +\gamma_{7} \text { flabr }_{i}+\gamma_{8} \text { fsize }_{i}+\gamma_{9} \text { alwday }_{i}+\gamma_{10} \text { agrwday }_{i}+\gamma_{11} \text { Re gion } \\
& +\gamma_{12} \text { Time }+v_{i}
\end{aligned}
$$

\footnotetext{
3 Even with very sophisticated methodologies, like Blinder's (1973) decomposition approach, the problem of excluding some important variables from the earning equation could well cause biaseddecomposition results.
} 
where flabr and fsize represent household female labour ratio and number of family members in a household respectively. The variables alwday and agrwday are average labour working days and the share of the agricultural production working days per household labourer, respectively. Region is a vector of regional dummy variables, and Time is a dummy variable for 1994.

To test the determinants of regional income differentials, Blinder's (1973) decomposition approach is used. Blinder developed the approach to analyse the issue of gender wage differential. We borrowed his approach to analyse the problem of regional income differential. Blinder decomposes gender wage differential into an explained portion, which is mainly due to gender endowment differentials, and an unexplained portion, which could be due to labour market discrimination. In our case, the explained portion is due to regional resource endowment differentials, such as human capital, available arable land and capital, family labour ratio and female labour ratio, etc. The unexplained portion can be called a regional premium, which could include the stage of economic development, the degree of marketisation, the openness of the regional economy and the location of a region.

Blinder's decomposition approach can be expressed as follows. Let the income of individual $i$ be expressed as

$$
W_{i}=\alpha_{0}+\beta_{i} X_{i}+\varepsilon_{i}
$$

and $X_{i}$ is a vector of $n$ observable characteristics used to explain $W$. Suppose we are interested in comparing incomes for two groups (either demographic or regional), then the income equation for each group can be written as:

$$
\begin{aligned}
& W_{i}^{1}=\alpha_{0}^{1}+\beta_{i}^{1} X_{i}^{1}+\varepsilon_{i}^{1} \\
& W_{i}^{2}=\alpha_{0}^{2}+\beta_{i}^{2} X_{i}^{2}+\varepsilon_{i}^{2}
\end{aligned}
$$

The mean income differential between the two groups can then be written as:

$$
\bar{W}_{i}^{1}-\bar{W}_{i}^{2}=\left(\hat{\alpha}_{0}^{1}-\hat{\alpha}_{0}^{2}\right)+\hat{\beta}_{i}^{1}\left(\bar{X}_{i}^{1}-\bar{X}_{i}^{2}\right)+\bar{X}_{i}^{2}\left(\hat{\beta}_{i}^{1}-\hat{\beta}_{i}^{2}\right)
$$

Here the first term is the unexplained portion. The second term is the difference in mean endowments possessed by the two groups as evaluated by the first group's wage equation. The last term is the coefficient differential between the two groups as evaluated at the second group's mean endowment level. According to Blinder (1973), the difference due to the coefficients (the third term), which exists only because the market treats the two groups with identical endowments differently, is also an unexplained portion. ${ }^{4}$

$4 \quad$ A further practical consideration associated with the adoption of Blinder's approach is the index number problem. This refers to the fact that the decomposition of the wage gap between two groups is 
In this study we work out the proportion of regional income differential which is attributable to the regional endowment differential and the proportion which can be attributable to regional premium. The latter includes the difference in returns to human capital, land, capital and other demographic variables among regions and the difference in intercepts, which can be a mixture of regional development, regional openness and the advantage or disadvantage of regional location.

\section{Household income determination and its differences among the five provinces}

Equation 9 was estimated for the effective samples using household net income, and per capita net income as dependent variables. The results are presented in Table 3. The specifications for different dependent variables are slightly different. As net income per capita reflects income redistribution within family members, the variable 'family size' is only added to this equation to capture the redistribution effect.

The adjusted $R^{2}$ for the total household income function is 0.51 . Generally speaking, the signs of all variables are as expected and statistically significant, except for capital. The share of labour and land contribution in household net income is 52.4 and 38.3 per cent, respectively. However, the income elasticity of capital is insignificant. This result seems to suggest that up until now, most rural household production is still land and labour intensive in that capital input does not significantly enhance output.

An increase in years of education per labourer by one year increases household net income (including net income from a household production and income earned elsewhere by the household members) by 5.9 per cent. This rate is much higher than that has been found in some other studies on the rate of return to education in China (see, for example, Gelb, 1990; Byron and Manaloto, 1990; Gregory and Meng, 1996).

The impact of average labour market experience on household income in rural China is significant at the margin. Its quadratic term, however, is not statistically significant. $^{5}$

not unique. In Equation (13) the weights used for the $C$ and $E$ terms are $\hat{\beta}_{i}^{1}$ and $\bar{X}_{i}^{2}$ respectively. These weights can be replaced by $\hat{\beta}_{i}^{2}$ and $\bar{X}_{i}^{1}$ to yield another weighted decomposition. The results for the two weighted decompositions are different (see Sloane, 1985). However, as this study concerns more about the ranking of decomposition obtained for different regions rather than the level of decomposition for each region, this index number problem can be ignored.

$5 \quad$ There might be a couple of possible explanations. First, the dependent variable used here is mixture of income earned from household agricultural or non-agricultural productions and earned elsewhere by household members, whereas the variable labour market experience is a average measure of total household labourers, which including both agricultural and non-agricultural experience. One may expect that in general agricultural work experience should not affect productivity in the 
On average, one more working day raises net income by 0.2 per cent, whereas increase in the ratio of average labour agricultural working days over total working days reduces net income dramatically. This finding suggests that agricultural production is very unproductive in terms of increasing household income. That is, the more non-agricultural activity involved in a household, the higher the household income is.

One interesting finding from the regression results is that the ratio of female labour over household total labour has positive and significant impact on household net income. This implies that when there is no market discrimination, ie. in the case of family production, female labourers may contribute more to the household income relative to their male counterparts. This finding may be consistent with the fact that more female labourers are working in the better-paid labour-intensive (such as textiles) rural manufacturing factories (Wu, 1994b).

As the dependent variable is deflated net income according to China's 1993 and 1994 rural CPIs for the 5 provinces, regional dummy variables reflect the real regional income differential. The ranking is the same as is shown in Table 2. The time dummy variable reflects the effect the real change of income over time.

The results of the equation of net income per capita have a similar structure as that for the net income equation in terms of signs, magnitude and significance except for the experience variables, which are insignificant for the income per capita equation. The most interesting finding for this equation, however, is the family redistribution effect. The variable 'family size' has a strong negative significant impact on per capita income. Given the household labour force, the impact of family size captures the effect of a change in household members on household net income. The magnitude of the coefficient indicates that increasing the number of household member by one will reduce household per capita income by 17.8 per cent, ceteris paribus. This huge redistribution effect could, in some way, be a pushing force for rural labour migration, especially for those who are highly educated young and male labourers. This is only a hypothesis that is yet to be tested. This paper, however, is unable to do so.

non-agricultural sector, and vice versa. Second, labour market experience in this study is measured using Mincer's (1974?) potential experience definition: texp=age-ysch-7. This may over-estimate female work experience as women may have discontinuous work experience. The measure used in this study is an average work experience per household labourer, which mixes male and female labourers in the household. Thus, the over-estimation of work experience of household per labourer may be another reason for the insignificant estimation. 
TABLE 3 Regression results for household income equations

\begin{tabular}{|c|c|c|}
\hline & $\begin{array}{l}\text { Household } \\
\text { total income }\end{array}$ & $\begin{array}{l}\text { Income } \\
\text { per capita }\end{array}$ \\
\hline Constant & $\begin{array}{l}5.318 \\
(24.93)\end{array}$ & $\begin{array}{l}4.884 \\
(22.66)\end{array}$ \\
\hline Average year of education of a labourer & $\begin{array}{l}0.059 \\
(7.70)\end{array}$ & $\begin{array}{l}0.058 \\
(7.47)\end{array}$ \\
\hline Average working experience of a labourer & $\begin{array}{l}0.015 \\
(1.63)\end{array}$ & $\begin{array}{l}0.007 \\
(0.81)\end{array}$ \\
\hline${\text { (Working experience })^{2}}^{2}$ & $\begin{array}{l}-0.0009 \\
(-0.537)\end{array}$ & $\begin{array}{l}0.0001 \\
(0.49)\end{array}$ \\
\hline $\ln ($ Labour $)$ & $\begin{array}{l}0.524 \\
(12.27)\end{array}$ & $\begin{array}{l}0.449 \\
(8.80)\end{array}$ \\
\hline $\ln ($ Capital) & $\begin{array}{l}-0.005 \\
(-0.36)\end{array}$ & $\begin{array}{l}-0.005 \\
(-0.37)\end{array}$ \\
\hline $\ln ($ Land $)$ & $\begin{array}{l}0.383 \\
(12.32)\end{array}$ & $\begin{array}{l}0.355 \\
(11.13)\end{array}$ \\
\hline Ratio of female labour to total labour & $\begin{array}{l}0.294 \\
(2.80)\end{array}$ & $\begin{array}{l}0.254 \\
(2.38)\end{array}$ \\
\hline Family size & & $\begin{array}{l}-0.178 \\
(-10.77)\end{array}$ \\
\hline Average labour working days & $\begin{array}{l}0.002 \\
(6.84)\end{array}$ & $\begin{array}{l}0.002 \\
(6.66)\end{array}$ \\
\hline Share of agricultural working days & $\begin{array}{l}-0.289 \\
(-4.20)\end{array}$ & $\begin{array}{l}-0.260 \\
(-3.74)\end{array}$ \\
\hline Guangdong & $\begin{array}{l}1.323 \\
(24.83)\end{array}$ & $\begin{array}{l}1.301 \\
(23.68)\end{array}$ \\
\hline Jilin & $\begin{array}{l}0.204 \\
(2.46)\end{array}$ & $\begin{array}{l}0.214 \\
(2.56)\end{array}$ \\
\hline Jiangxi & $\begin{array}{l}0.481 \\
(8.76)\end{array}$ & $\begin{array}{l}0.469 \\
(8.46)\end{array}$ \\
\hline Shandong & $\begin{array}{l}0.567 \\
(10.39)\end{array}$ & $\begin{array}{l}0.583 \\
(10.56)\end{array}$ \\
\hline 94 dummy & $\begin{array}{l}0.276 \\
(9.14)\end{array}$ & $\begin{array}{l}0.275 \\
(9.04)\end{array}$ \\
\hline Adjusted $R^{2}$ & 0.51 & 0.44 \\
\hline Number of observations & 1622 & 1622 \\
\hline
\end{tabular}

Source: Authors' own estimation.

Notes: The figures in parentheses are t-statistics.

The two income equations are then estimated for the five provinces separately and the results are presented in Tables B1 and B2, Appendix B. The basic structure of the net income equation is about the same for the provinces separately as it is for the total sample (see Table B1 of Appendix B). However, there are some noticeable differences.

The impact of labour market experience is insignificant for Jiangxi, Sichuan and Shandong. It has increasing returns for Jilin (the quadratic term is not statistically 
significant) and U-shape for Guangdong. ${ }^{6}$ Except for Guangdong, the income elasticities of capital is insignificant for all the regions.

The 'female labour ratio' is not significantly correlated with household net income for Guangdong, Jilin and Sichuan, but positive and significant for Jiangxi and Shandong. These reinforce the conjecture that the female labour force contributes equally, if not positively, to family income when compared to their male counterparts. It is found that whether family labour force is engaged in agricultural or other productions brought little difference in household income in Shandong Province.

As for the net income per capita equation (Table B2 of Appendix B) the differences mentioned above stay the same. However, the income elasticity of land for Sichuan is negative and marginally significant in this case. The result is indeed very puzzling in that one would expect that in a region like Sichuan, where land is very scarce, the return to land should be high. This requires further study.

In general, the ranking of the coefficients for each main independent variable for the total household income equation is shown in Table 4, where the sum of labour, capital and land reflects the local returns to scale. Although Jiangxi has the highest starting income, its return to education and local returns to scale are all rank last. This pattern generally holds for the net income per capita equation. It is, however, worthwhile to mention that the ranking for the household redistribution effect (number of household member) is Shandong, Guangdong, Jilin, Jiangxi and Sichuan.

TABLE 4 Ranking of the importance of the main variables across regions

\begin{tabular}{l|ccccc}
\hline & GD & JL & JX & SC & SD \\
\hline Intercept & 2 & 4 & 1 & 5 & 3 \\
Education & 4 & 2 & 5 & 1 & 3 \\
\cline { 1 - 1 } Labour+capital+land & 1 & 2 & 5 & 3 & 4 \\
\hline
\end{tabular}

\section{The causes of the dispersion of income among the regions}

The analysis up to this point provides a general picture on how the household income is determined and the differences of these determinants among the five provinces. This analysis, however, did not provide accurate calculation as to how much of the regional

\footnotetext{
6 The peculiar experience-income profile for Guangdong is hard to explain. The complication is from the measurement of both the income and experience variables. In Guangdong, the case is especially complicated because more people there is involved in the non-agricultural production than in the other regions.
} 
income differential is due to a regional endowment difference and how much is due to a regional premium. Blinder's decomposition approach described in Section 3, however, will enable us to scrutinise this issue.

As there are five provinces in our sample, we rank them by their income level and use the province with the highest income as the norm. In our case, Guangdong is used as the base of comparison.

The net income differential between Guangdong and any other province is decomposed into three components: the differential due to the intercept difference, the coefficient difference, and the regional endowment difference. The first two components together can be called the regional premium. ${ }^{7}$ Among them, the first portion (the intercept difference) may be attributed to a mixture of the stage of regional economic development, the degree of regional marketisation, the degree of openness of the regional economy and any thing else that is related to the advantage or disadvantage of regional location. The second component reflects the difference of market evaluation of return to household inputs. The third component is the portion of the income differential which can be attributable to regional endowment or input differential, which is often called the explained portion. One can then compare each portion of these differences with the total income differential between Guangdong and any other province to determine what proportion of each component accounts for the total income differential, then compare the results across the four provinces (excluding Guangdong).

The results of Blinder's decomposition for household net income are presented in Table 5. As every province in Table 5 is compared to Guangdong, the total differentials there indicate the household net income differential between Guangdong and each of the other provinces, where income is measured in logarithmic term. The negative value in Table 5 denotes the advantage of a province relative to Guangdong.

7 These two components are often called 'the unexplained portion' in gender wage differential literature. 


\begin{tabular}{l|rrrrrrrrr}
\multicolumn{1}{c}{ TABLE 5 Decomposed regression results for regional household income differentials } \\
\cline { 2 - 10 } & \multicolumn{3}{|c}{ Jilin } & \multicolumn{1}{c}{ Jiangxi } & Sichuan & \multicolumn{2}{c}{ Shandong } \\
\cline { 2 - 10 } & value & $\%$ & value & $\%$ & value & $\%$ & value & $\%$ \\
\hline Household income & & & & & & & & \\
Total differential & 1.125 & 100 & 0.950 & 100 & 1.570 & 100 & 0.849 & 100 \\
Regional premium & 1.159 & 103.0 & 0.866 & 91.2 & 1.188 & 75.7 & 0.759 & 89.4 \\
Intercept difference & 1.091 & 97.0 & -0.065 & -6.8 & 1.512 & 96.3 & 0.423 & 49.8 \\
Coefficients & 0.068 & 6.0 & 0.931 & 98.0 & -0.324 & -20.6 & 0.336 & 39.6 \\
Endowments & -0.033 & -3.0 & 0.084 & 8.8 & 0.382 & 24.3 & 0.090 & 10.6 \\
\hline
\end{tabular}

The results presented in Table 5 based upon the household net income regression suggest that the regional premium of Guangdong relative to the other provinces is ranked as follow: Jilin, Jiangxi, Shandong, and Sichuan. This implies that the unexplained portion of income differential over the total income differential between Guangdong and the other provinces is highest for Jilin, and then Jiangxi, Shandong, and Sichuan. Apart from Sichuan, the ranking do reflect the stage of economic development, the degree of marketisation, and the level of openness of each regional economy relative to Guangdong.

According to the analysis undertaken in Section 2, the level of economic development and the degree of marketisation in Sichuan is fairly low. Surprisingly, the regional premium of Guangdong relative to Sichuan is the lowest among the 4 provinces. However, if the results shown in Table 5 are read carefully, it is easy to find that this surprising result is due to the fact that the income differential between Guangdong and Sichuan is much greater than that between Guangdong and the other provinces.

This surprising result suggests that when the magnitude of the total income differential between Guangdong and each of the other provinces is different, the proportion of each component accounting for the total differential could give a misleading impression. To avoid this kind of misconception, we developed an index to double check the results obtained from Blinder's decomposition approach.

The basic idea of the index is to use estimated coefficients for the base region (Guangdong, in our case) and actual input levels for each of the other regions, thereby, to get a predicted income level for each of these regions. This predicted income level suggests how much a household in another region would have earned if they moved their endowments to the base region (Guangdong). The ratio between the actual income level and the predicted income level for each region captures the efficiency of each 
region in terms of household production and off-household labour earning. The index can, therefore, be called regional advantage index, which is defined as follows:

$$
E=\left(\alpha_{0}^{A}+\sum_{i}^{n} \beta_{i}^{A} X_{i}^{A}\right) / \hat{\alpha}_{0}^{B}+\sum_{i}^{n} \hat{\beta}_{i}^{B} X_{i}^{A}
$$

where the superscripts $B$ and $A$ represent the base region and the region analysed in the study, respectively. The numerator is the actual income for region $A$ and the denominator is the predicted income for region $A$. The results for the regional advantage indices are presented in Table 6.

TABLE 6 Results for regional advantage index

\begin{tabular}{l|ccc}
\hline & \multicolumn{3}{|c}{ Household net income } \\
\cline { 1 - 1 } & Actual & Predicted & Index \\
\cline { 1 - 1 } Jilin & 8.10 & 9.26 & 0.87 \\
\cline { 1 - 1 } Jiangxi & 8.28 & 9.14 & 0.91 \\
\cline { 1 - 1 } Sichuan & 7.66 & 8.84 & 0.86 \\
Shandong & 8.38 & 9.14 & 0.92 \\
\hline
\end{tabular}

Although Sichuan's household income is the lowest of all the provinces, a quarter of the income difference between Guangdong and Sichuan can be attributed to the endowment differential. This leads to a smaller share of regional premium (75 per cent) to the total income gap. Among the unexplained portion (regional premium), the major contributor is the intercept difference, which attributes for 96 per cent of the gap (see Table 5, column 6). However, the advantage index precented in Table 6 suggests that the actual income a household in Sichuan earned is only 86 per cent of what it would have earned in Guangdong had it moved to Guangdong with the exactly same endowments, which is the lowest among all the provinces. This indicates that although the total unexplained portion of the income differential is relatively small, the inefficient use of the possessed resource endowments played a significant part in explaining the income differential between Sichuan and Guangdong.

Jilin has the second lowest household income among the five provinces. However, its endowments are actually higher than that in Guangdong. This implies that the endowments in Jilin are used less efficiently than that of Guangdong. The regional premium for Guangdong relative to Jilin explains 103 per cent of the income gap between the two regions. The advantage index implies that the actual income a household in Jilin earned is only 87 per cent of what it would have earned should the household lived in Guangdong with the same endowments. The fact that households in 
Jilin with higher resource endowments earned much less income than their counterparts in Guangdong may suggest that the lack of reform and openness might have played an important role in regional income differential.

The income gap between Guangdong and Shandong is the smallest among all the provinces. About 11 per cent of the gap can be attributable to the inferior of Shandong's resource endowments relative to Guangdong's. The regional premium accounts for about 89 per cent of the total income gap. Here, the regional premium might be explained by the fact that Shandong implemented reform and an open door policy about 5 years later than Guangdong. This could be a negative externality to Shandong's economic development. In addition, Shandong may have some pure locational disadvantage. The advantage index indicates that among all the provinces a household in Shandong is the closest to Guangdong in terms of efficiently using its endowment (its actual income account for 92 per cent of its predicted income, see Table $6)$.

Interestingly, the information obtained from the decomposition results for Jiangxi shows that the majority of the income differential between Guangdong and Jiangxi is from the difference in return to inputs. The return to inputs in Jiangxi is so low that about 98 per cent of the net income differential is explained by the coefficient differential between the two provinces.

\section{Conclusions and Policy Implications}

In this study, using recent sample survey data on rural households of five Chinese provinces, household net income and household net income per capita equations were estimated to examine rural household income determination. Based on the regression results, Blinder's decomposition approach was used to examine the causes of income dispersion across the surveyed provinces. In addition, a regional advantage index was also developed to measure regional premium. From the empirical findings, some concluding remarks and policy implications can be drawn.

It has been found that labour and land, as traditional production inputs, still play a dominant role in determining China's rural household income. Compared with land, labour is much more important. This means that most income-generating activities in rural China are still labour intensive, which is associated with the nature of China's factor endowment. For most on-farm production the high labour-land ratio has determined the substitution of labour for farm machines both technically and economically. This is clearly reflected by the difference in marginal productivity of labour, land and capital between Jilin where the labour-land ratio is relatively low and other provinces surveyed where the same ratio is relatively high (derived from Table 2 ). 
This suggests that increasing agricultural labour productivity by increasing the use of modern farm machinery is only possible when the labour-land ratio falls as economic development shifts more labour away from the farm sector while merging small plots into larger ones. The greater contribution of capital to household income found in Guangdong in comparison to that of the other provinces with high labour-land ratios, provided support for this argument.

This study has also found that, while the quantity of labour input has maintained its importance, the quality of labour has increased its role in determining China's rural household income. The increase in an average labourer's education level has had a significant positive income effect. Since the increasing role of the quality of labour in determining China's rural household income is associated with the decrease in the agricultural share of total working days, particularly in the fast growing coastal provinces, it suggests that better-educated labour has been more important in off-farm income-generating activities. Obviously, raising both the general and occupational education level of the rural population will help increase rural household income, as well as equalising income distribution across regions.

There are other interesting findings from the income determination analysis, although their policy implications may need more empirical tests. For example, this study has found that female labourers have played the somewhat more important roles as their male counterparts in determining China's rural household income. This supports the argument that a rural household, which functions as an individual economic agent optimising its resource use, has no gender bias in seeking to maximise its profits. This may suggest that, given the current household farming system in China education and other occupational training for female population will have the same, if not more important, effect on household income as for male population. Our analysis also found that, given the number of labourer, the size of a family has a significant negative income redistribution effect on China's rural household per capita income, suggesting that the larger the family, the lower the per capita income. In turn, the size of families may have functioned as one of strong pushing forces for rural out-migration in China.

Using Guangdong as a benchmark, the decomposition results and the advantage index developed in this study indicate that the majority of income differential between Guangdong and other provinces surveyed due to difference in the efficiency of input use. This analysis also suggests that the households from other provinces would have earned 10 to 20 per cent more if they had been in Guangdong. The high return to factor inputs in Guangdong partially reflects a locational advantage that other provinces may never be able to obtain. However, on the other hand, and perhaps more importantly, the 
majority of the high return to factor inputs in Guangdong may have been attributable to the less restricted policy device in production and marketing and more openness to trade in Guangdong than that in other provinces surveyed. If so, this may suggest that further economic reform and opening up of regional economies can reducing rural income dispersion among the regions of China. The fact that most regions in this study have lower factor returns than that in Guangdong also suggests that the open up of inter-regional trade and factor mobility is necessary for improving regional income distribution in China. 


\section{Appendix A: The sampling procedure and data description}

\section{- The sampling procedures}

The data set used in this study is from a grain farm household sample survey in 1993-94 on about 1000 rural households of China's five provinces, namely Guangdong, Jilin, Jiangxi, Sichuan and Shandong. This survey was jointly conducted by the Chinese Economy Research Unit, University of Adelaide, Australia (CERU) and Ministry of Agriculture, China (MoA), as a part of ACIAR (Australian Centre for International Agricultural Research) research project on China's grain production, marketing and consumption. The five provinces are considered to be able to represent the regional differentials in grain production, consumption and marketing of south, northeast, central, southwest and east China, respectively (Wu, 1996).

The CERU-MoA survey was based on the existing crop-cost survey conducted annually by each province under the instruction of the MoA. The sample counties or villages or households in the crop-cost survey are selected from the "qualified" population of counties or villages or households. To be qualified a county or village or household has to produce any one or more of the following crops as its major $\operatorname{crop}(\mathrm{s})$ : wheat, maize, rice, soybean, rapeseeds, sugar cane, sugar beetroot, peanut and cotton. Qualified counties or villages or households are then ranked by yield of per $m u$ by crop and selected by the equidistant sampling method (Wu, 1996).

The sampling of the CERU-MoA survey in the five selected provinces is based on the population of the samples qualified for grain production in the crop-cost survey. So, it is simply grain-focused. Generally, the selected samples should be able to represent the average level of grain production of the administrative area to which they belong. For example, the selected counties should be able to reflect the average level of grain production of the provinces to which they belong.

There were also other biases in the sampling procedures. For example, a village was selected if the village accountants were qualified and willing to cooperate. However, MoA gave no clear criteria for the qualification of village accountant. The judgment was made by local authorities and was apparently based on officials' experiences with local accountants. Besides, a household was selected if a member of the household could literally answer most of the survey questions. These mean that there might be some qualified samples by the criteria of grain production to be excluded by the criteria of the qualification of village accountant and the level of household literacy.

The survey was designed to collect 1000 effective household samples, equally selected from 4 sampled counties of each of the five provinces. It eventually collected 
1041 samples for the 1993 production year and 1013 for the 1994 production year. To match the two years for simple descriptive statistics, only 938 samples are effective (Table 2). However, to satisfy our empirical analysis, only 811 samples are effective (Table 3).

\section{- Data description}

The number of observations actually used in this study is the number of effective observations that allow the comparison between the data collected in both 1993 and 1994, and the logarithmic transformation of the data. There are 840 observations for each year actually used in the estimation of the model.

The variables used in the model and their derivations are explained as follows. The abbreviation of each variable used in the model is given in the first pair of brackets and the unit of each variable is given in the second pair of brackets.

Dependent variable:

Household Net Income (HNI) (yuan) is obtained by subtracting income-related costs from rural household gross income, including income from both within- and outside-family production activities, for each province. To eliminate price effect from the income variable, (1) provincial difference in inflation in 1993 and 1994 is adjusted by the deviation of rural retail price index (RRPI) of each province from the national RRPI for 1993 (the 1994 provincial data are not available); and (2) the adjusted provincial income data for 1993 and 1994 are further deflated by a national deflator (RRPI). ${ }^{8}$ The income data used in the model estimation are in 1992 price.

Household Net Income Per Capita (HNI) (yuan) is obtained by dividing the deflated rural household net income by number of household members.

\section{Independent variable:}

Labour ( $L$ ) (person) is the number of labourers in a household, which is defined as those aged 15-74 and working 10 or more days a year. The working age range used is 10 more years than the widely used definition (15-64). We argue that 10 more years of working experience can make a significant contribution to agricultural, particularly grain, production. In fact, the survey results show that people aged 64-74 who were still working mainly engaged in on-farm activities. As any definition for labour force, our definition is also arbitrary. The

8 The deviation of each province's RRPI from the national RRPI (=1) is 1.04 for Guangdong, 0.96 for Jilin, 0.98 for Jiangxi, 1.01 for Sichuan and 0.97 for Shandong. The national RRPI (the previous year=100) is 112.6 for 1993 and 122.9 for 1994 (CSSB, 1994, pp. 17-9; pp. 34-5; CSSB, 1995, p. 46). 
minimum level of 10 working days is chosen, because such a period is sufficient for an adult labourer to complete a major farm work.

Capital $(K)$ (yuan) is the fixed capital stock of a household. To eliminate price effect from the capital variable, (1) provincial difference in inflation in 1993 and 1994 is adjusted by the deviation of agricultural producers goods price index (APPI) of each province from the national APPI for 1993 (the 1994 provincial data are not available); and (2) the adjusted provincial capital data for 1993 and 1994 are further deflated by a national deflator (APPI). ${ }^{9}$ The capital data used in the model estimation are in 1992 price.

Land $(A)(m u)$ is the area of arable land contracted by a household.

Education (edu) (year) is measured as the average years of schooling per household labourer.

Experience (exp) (year) is average potential years of labour market experience per household labourer, which is measured by average age of per household labourer minus seven (the age children start school in China) minus average years of schooling per household labourer.

Rate of female labour (flab) $(\%)$ is measured as the total number of household female labourer divided by the total number of household labourer.

Family size (fsize) (person) is the total number of people in a household.

Average labour working days (alwday) (day) is measured as the total working days of a household divided by the number of labourer of the household.

Rate of agricultural working days (agrwday) (\%) is measured as the total agricultural working days of a household divided by the total working days of the household.

9 The deviation of each province's APPI from the national APPI $(=1)$ is 0.99 for Guangdong, 0.96 for Jilin, 0.97 for Jiangxi, 1.01 for Sichuan and 0.98 for Shandong. The national APPI (the previous year=100) is 114.1 for 1993 and 121.6 for 1994 (CSSB, 1994, pp. 17-9; pp. 34-5; CSSB, 1995, p. 46). 


\section{Appendix B:}

Table B1 Regression results of total income equation for each of the five provinces

\begin{tabular}{lrrrrr}
\hline & GD & JL & JX & SC & SD \\
\hline Constant & 6.664 & 5.573 & 6.729 & 5.153 & 6.241 \\
& $(15.85)$ & $(8.81)$ & $(14.76)$ & $(7.74)$ & $(20.05)$ \\
Year of education per labourer & 0.050 & 0.065 & 0.046 & 0.082 & 0.064 \\
& $(2.83)$ & $(3.55)$ & $(2.73)$ & $(3.11)$ & $(4.98)$ \\
Experience per labourer & -0.034 & 0.042 & 0.002 & 0.023 & 0.016 \\
& $(-1.75)$ & $(1.91)$ & $(0.12)$ & $(0.87)$ & $(1.07)$ \\
Experience & 2.0007 & -0.0005 & 0.0001 & -0.0002 & -0.0002 \\
& $(2.02)$ & $(-1.40)$ & $(0.29)$ & $(-0.33)$ & $(-0.61)$ \\
ln(Labour) & 0.557 & 0.439 & 0.423 & 0.932 & 0.517 \\
& $(7.20)$ & $(3.20)$ & $(4.25)$ & $(7.37)$ & $(7.22)$ \\
ln(Capital) & 0.050 & 0.020 & -0.035 & -0.01 & 0.00001 \\
& $(2.01)$ & $(0.49)$ & $(-0.95)$ & $(-0.28)$ & $(0.001)$ \\
ln(Land) & 0.526 & 0.438 & 0.180 & -0.061 & 0.261 \\
& $(12.21)$ & $(4.97)$ & $(2.54)$ & $(-0.43)$ & $(3.94)$ \\
Female labour/total labour & 0.110 & 0.228 & 0.588 & 0.395 & 0.309 \\
& $(0.57)$ & $(0.72)$ & $(2.68)$ & $(1.49)$ & $(1.80)$ \\
Average labour working days & 0.003 & 0.001 & 0.001 & 0.002 & 0.0004 \\
& $(5.61)$ & $(1.17)$ & $(2.72)$ & $(1.62)$ & $(0.77)$ \\
Rate of agricultural working days & -0.432 & -0.782 & -0.337 & -0.568 & 0.025 \\
& $(-3.66)$ & $(-3.01)$ & $(-2.31)$ & $(-2.88)$ & $(0.21)$ \\
Dummy variable for 1994 & 0.220 & -0.105 & 0.387 & 0.628 & 0.307 \\
& $(3.83)$ & $(-1.19)$ & $(6.01)$ & $(7.24)$ & $(6.81)$ \\
\hline Adjusted $R^{2}$ & 0.48 & 0.16 & 0.20 & 0.36 & 0.33 \\
Number of observations & 328 & 316 & 348 & 268 & 362 \\
\hline
\end{tabular}


Table B2 Regression results of income per capita equation for each of the five provinces

\begin{tabular}{lrrrrr}
\hline & GD & JL & JX & SC & SD \\
\hline Constant & 6.068 & 5.115 & 6.131 & 4.873 & 5.959 \\
& $(13.85)$ & $(8.06)$ & $(13.30)$ & $(7.27)$ & $(19.17)$ \\
Year of education per labourer & 0.054 & 0.061 & 0.047 & 0.077 & 0.066 \\
& $(3.04)$ & $(3.34)$ & $(2.79)$ & $(2.88)$ & $(5.07)$ \\
Experience per labourer & -0.039 & 0.035 & -0.006 & 0.015 & 0.007 \\
& $(-2.01)$ & $(1.58)$ & $(-0.29)$ & $(0.57)$ & $(0.45)$ \\
Experience & 0.0009 & -0.0004 & 0.0004 & -0.00003 & 0.00002 \\
& $(2.48)$ & $(-0.99)$ & $(0.89)$ & $(-0.06)$ & $(0.10)$ \\
ln(Labour) & 0.565 & 0.337 & 0.359 & 0.715 & 0.482 \\
& $(6.29)$ & $(2.05)$ & $(3.29)$ & $(4.75)$ & $(5.73)$ \\
ln(Capital) & 0.044 & 0.020 & -0.036 & 0.002 & -0.001 \\
& $(1.76)$ & $(0.47)$ & $(-0.99)$ & $(0.06)$ & $(-0.07)$ \\
ln(Land) & 0.518 & 0.421 & 0.152 & -0.279 & 0.248 \\
Female labour/total labour & $(11.73)$ & $(4.75)$ & $(2.08)$ & $(-1.75)$ & $(3.62)$ \\
& 0.077 & 0.199 & 0.536 & 0.367 & 0.256 \\
Number of household member & $(0.39)$ & $(0.62)$ & $(2.34)$ & $(1.37)$ & $(1.49)$ \\
& -0.186 & -0.166 & -0.154 & -0.097 & -0.225 \\
Average labour working days & $(-6.72)$ & $(-3.91)$ & $(-4.67)$ & $(-1.66)$ & $(-7.46)$ \\
Rate of agricultural working days & 0.003 & 0.001 & 0.001 & 0.001 & 0.0004 \\
Dummy variable for 1994 & $(5.57)$ & $(1.16)$ & $(2.67)$ & $(1.11)$ & $(0.78)$ \\
& -0.428 & -0.772 & -0.296 & -0.523 & 0.054 \\
Adjusted R ${ }^{2}$ & $(-3.56)$ & $(-2.97)$ & $(-1.99)$ & $(-2.63)$ & $(0.47)$ \\
Number of observations & 0.215 & -0.102 & 0.392 & 0.633 & 0.302 \\
& $(3.69)$ & $(-1.15)$ & $(6.02)$ & $(7.23)$ & $(6.71)$ \\
\hline
\end{tabular}




\section{References:}

Becker, G. S., 1962. "Investment in Human Capital: A Theoretical Analysis", Journal of Political Economy. 70 (5) pt. 2, pp. 9-49.

Blinder, A. S., 1973. "Wage Discrimination: Reduced Form and Structural Estimations", The Journal of Human Resources, 8, pp. 436-55.

Byron, R. P. and Manaloto, E. Q., 1990, "Return to Education in China", Economic Development and Cultural Change, 38, pp. 783-796.

Caballe, J., 1993, “On Endogenous Growth with Physical and Human Capital” Journal of Political Economics, 101(6).

Datta, G. and Meerman, J., 1980, "Household Income or Household Income per capita in Welfare Comparisons" Review of Income and Wealth, 28, pp. 401-418.

Gelb, A., 1990. "TVP Workers' Incomes, Incentives, and Attitudes", in W.A. Byrd and Q. Lin (eds), China's Rural Industry. Oxford: Oxford University Press. pp. 280-98.

Kuznets, S. S., 1976, "Demographic Aspects of the Size Distribution of Income: An Exploratory Essay, Economic Development and Cultural Change, 25(1), pp. $1-94$.

Gregory, R. R. and Meng, X., 1996, "Wage Determination and Occupational Attainment in the Rural Industrial Sector of China", Journal of Comparative Economics, forthcoming.

Lucas, R. E., 1988, "On the Mechanics of Economic Development" Journal of Monetary Economics, 22, pp. 3-42.

Mincer, J., 1974. Schooling, Experience and Earnings. New York: National Bureau of Economic Research.

Romer, P. M., 1986, “Increasing Returns and Long-run Growth”, Journal of Political Economics,

1990, "Endogenous Technological Change", Journal of Political Economics, 93(5).

Sloane, P. J., 1985. "Discrimination in the Labour Market" Chapter 3 in R. Millward, M. T. Sumner and G. Zis (ed.) Labour Economics, New York: Longman Group Limited.

CSSB (State Statistical Bureau of China), various issues, Chinese Statistical Yearbook, Beijing: Chinese Statistical Press.

Wu, H. X., 1994a, "Rural Enterprise Contribution to Growth and Structural Change", in Findlay, Watson and Wu (eds.), Rural Enterprises in China, London: Macmillan Press

1994b, "The Rural Industrial Enterprise Workforce", in Findlay, Watson and Wu (eds.), Rural Enterprises in China, London: Macmillan Press 1996, "A note on the CERU-MoA grain farm household survey in China", China Economic Review, Vol 7(2), pp. 97-104. 